\title{
Divergent Role of Sphingosine 1-Phosphate on Insulin Resistance
}

\author{
Susann Fayyaz Lukasz Japtok Burkhard Kleuser \\ Faculty of Mathematics and Natural Science, Institute of Nutritional Science, \\ Department of Toxicology, University of Potsdam, Potsdam, Germany
}

\section{Key Words}

Sphingosine 1-phosphate (S1P) • Insulin resistance $\bullet$ Ceramides $•$ Diacylglycerol (DAG) $\bullet$ Nonesterified fatty acids (NEFA) • Hepatocytes $\bullet$ Pancreatic cells $\bullet$ Skeletal muscle cells

\begin{abstract}
Insulin resistance is a complex metabolic disorder in which insulin-sensitive tissues fail to respond to the physiological action of insulin. There is a strong correlation of insulin resistance and the development of type 2 diabetes both reaching epidemic proportions. Dysfunctional lipid metabolism is a hallmark of insulin resistance and a risk factor for several cardiovascular and metabolic disorders. Numerous studies in humans and rodents have shown that insulin resistance is associated with elevations of non-esterified fatty acids (NEFA) in the plasma. Moreover, bioactive lipid intermediates such as diacylglycerol (DAG) and ceramides appear to accumulate in response to NEFA, which may interact with insulin signaling. However, recent work has also indicated that sphingosine 1-phosphate (S1P), a breakdown product of ceramide, modulate insulin signaling in different cell types. In this review, we summarize the current state of knowledge about S1P and insulin signaling in insulin sensitive cells. A specific focus is put on the action of S1P on hepatocytes, pancreatic $\beta$-cells and skeletal muscle cells. In particular, modulation of S1P-signaling can be considered as a potential therapeutic target for the treatment of insulin resistance and type 2 diabetes.
\end{abstract}

\section{Introduction}

Insulin resistance is defined clinically as the inability of insulin to increase glucose uptake and utilization in insulin-sensitive tissues. In fact, insulin resistance has been acknowledged for decades as a hallmark of type 2 diabetes, which is distinguished by the typical 


\section{Cellular Physiology and Biochemistry}

Cell Physiol Biochem 2014;34:134-147

\begin{tabular}{l|l}
\hline DOI: $10.1159 / 000362990$ & (C) 2014 S. Karger AG, Basel
\end{tabular}

Published online: June 16, 2014

www.karger.com/cpb

Fayyaz/Japtok/Kleuser: S1P and Insulin Signaling

triad of hyperinsulinemia, hyperglycemia and hypertriglyceridemia [1]. Diverse measurements of plasma glucose and insulin levels are applied to detect insulin resistance, with the hyperinsulinemic euglycemic clamp being used as gold standard [2].

An enhanced requirement for insulin due to insulin resistance in divergent tissues may result in the development of hyperglycemia. However, due to the fact that pancreatic $\beta$-cells compensate for insulin resistance by hypersecretion of insulin, there is a period of normal or near-normal plasma glucose levels in an early phase of insulin resistance. This phase is followed by a $\beta$-cell failure, which is a result of an inadequate expansion of $\beta$-cell mass or failure of the existing $\beta$-cells to respond to glucose. In the liver, insulin resistance is connected with an unrestrained hepatic glucose production, which is a result of a diminished efficacy of insulin to suppress hepatic gluconeogenesis and glycogenolysis, while reduced hepatic glucose clearance results from impaired insulin-dependent stimulation of glycogen synthesis [3]. Skeletal muscle contributes for a great part of glucose utilization in the insulin-dependent postprandial phase. Therefore, insulin resistance in muscle cells due to a reduced uptake via the glucose transporter GLUT4 and an impaired glucose utilization plays a crucial role in the homeostasis of plasma glucose levels [4].

An understanding of insulin resistance on the molecular level, requires knowledge of the mechanisms of insulin action in peripheral tissues. Insulin activates the insulin receptor (IR) tyrosine kinase, which phosphorylates and recruits several substrate molecules such as the insulin receptor substrate (IRS) protein family. Activated IRS then displays binding sites for several signaling molecules containing the conserved Src Homology 2 (SH2) domain. Among them, the activation of the phosphatidylinositide 3-kinase $\left(\mathrm{PI}_{3} \mathrm{~K}\right) /$ Akt-pathway has a central role in insulin function. Thus, stimulation of Akt mediates glycogen synthesis in liver

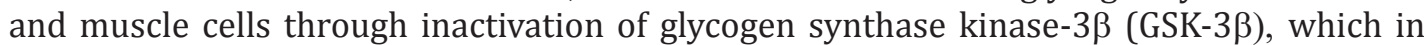
turn phosphorylates and inactivates glycogen synthase [5]. In addition, insulin signaling inhibits gluconeogenesis in the liver through disruption of the cAMP response element binding protein (CREB), which is modulated at least in part via the CREB regulated transcription coactivator 2 (TORC2) [6]. Moreover, the Akt-signaling pathway is involved in insulin-mediated protein synthesis via the mammalian target of rapamycin (mTOR) that additionally regulates cell growth, proliferation and survival [7]. Insulin inhibits several proapoptotic effector proteins such as Bcl-2 family member Bad, Forkhead family transcription factors, and GSK-3, which is essential for cell survival [8]. Glucose uptake in muscle and adipocytes in response to insulin includes translocation of GLUT4 via the $\mathrm{PI}_{3} \mathrm{~K} /$ Akt-pathway. This is connected with the phosphorylation of a $160 \mathrm{kDa}$ substrate (AS160 also called Tbc1d4), which regulates GLUT4 translocation through its GAP activity (GTPase-activating protein) [9].

The association between lipids and insulin resistance is widely accepted. Non-esterified fatty acids (NEFA) are elevated in obesity and are an independent marker of future type 2 diabetes mellitus. Several studies have indicated that palmitate, the most abundant saturated fatty acid in plasma, contributes to insulin resistance in liver, muscle and $\beta$-cells [10]. Upon entry into hepatocytes, fatty acids are rapidly esterified with coenzyme A to fatty acylCoAs, which can either be shuttled into $\beta$-oxidation or be transferred to a glycerol backbone resulting in the formation of mono-, di-, and triglycerides [11]. Especially, the formation of diacylglycerols (DAG) has been connected to insulin resistance, which has been reviewed extensively [12]. DAG-mediated protein kinase $\varepsilon(\mathrm{PKC} \varepsilon$ ) activation has been linked to insulin resistance in several rodent models and in humans [13]. Thus, PKC $\varepsilon$ may interrupt insulin signaling via serine/threonine phosphorylation of the IR [14]. Moreover, it is well known that the saturated fatty acid palmitate is necessary for the de novo synthesis of ceramides [15]. Several lines of evidence support a role of these lipids and glucosylceramides in the pathogenesis of insulin resistance via activation of atypical PKCs such as PKC $\zeta$, which interferes with insulin signaling [16].

Additionally, it has been suggested that ceramide formation in response to palmitate can also occur due to a stimulation of the toll-like receptor 4 (TLR4). Especially saturated fatty acids are agonists for TLR4, which upon stimulation leads to an upregulation of the de novo ceramide synthesis enzymes, synthesis of ceramides and ceramide-induced activation 


\section{Cellular Physiology and Biochemistry}

Cell Physiol Biochem 2014;34:134-147

\begin{tabular}{l|l}
\hline DOI: $10.1159 / 000362990$ & (C) 2014 S. Karger AG, Basel
\end{tabular}

Fayyaz/Japtok/Kleuser: S1P and Insulin Signaling

of protein phosphatase $2 \mathrm{~A}$ inhibiting directly Akt phosphorylation $[17,18]$. A central role of ceramides has been shown for several biological effects like cell growth arrest, apoptosis and differentiation [19]. Although ceramides can be recycled back to sphingomyelin a further degradation and metabolising occur concurrently. Ceramidases are the most important enzymes in degrading ceramides yielding to the free sphingoid base. Sphingosine kinases (SphK) are responsible for the phosphorylation of sphingosine resulting in the formation of sphingosine 1-phosphate (S1P). This molecule is a potent signal mediator that affects multiple cellular functions important for health and disease. The multitude of different S1P-mediated actions can be explained by the fact that the sphingolipid on the one hand modulates intracellular functions and on the other hand acts as ligand of $\mathrm{G}$ protein-coupled receptors (GPCR) after secretion into the extracellular environment. Until now five high-affinity receptors for S1P, designated $\mathrm{S}_{1} \mathrm{P}_{1}-\mathrm{S}_{1} \mathrm{P}_{5}$, have been identified [20]. Two isoforms of SphK have been discovered, named type 1 and 2 , both are widely expressed and therefore regulate the level of S1P [21, 22]. There exist a rapidly growing number of agonists that have been identified to stimulate SphK-activity. Most of them are involved in the regulation of cell growth and survival. Platelet derived growth factor, epidermal growth factor, vascular endothelial growth factor, nerve growth factor and even insulin are typical stimuli to activate SphK1 $[23,24]$. The degradation of S1P is controlled either by specific and non-specific phosphate phosphohydrolases, which hydrolyze S1P to sphingosine [25, 26], or by the S1P-lyase, cleaving S1P into hexadecenal and phosphoethanolamine [27].

In addition to the well known increase in plasma triglycerides and NEFA levels as predictor of insulin resistance, elevation of S1P plasma levels have been recently recognized as a critical feature of both human and rodent obesity [28]. Moreover, S1P levels correlate with metabolic abnormalities such as adipositas and insulin resistance [29]. Several studies suggest that S1P has divergent action on insulin signaling depending on the cell type. Therefore, we will focus on selected recent advances in understanding the role of S1P on insulin signaling in hepatocytes, muscle and pancreatic $\beta$-cells.

\section{Role of S1P on hepatic insulin resistance}

The liver plays a central role in glucose homeostasis and metabolism of lipids and amino acids. A chronic lipid oversupply of the liver is accompanied by excess lipid deposition called steatosis, an early form of nonalcoholic fatty liver disease (NAFLD). There is close correlation between hepatic steatosis and the development of insulin resistance.

Under physiological conditions the low steady-state triglyceride concentrations in the liver are attributable to a precise balance between acquisition by uptake of NEFA from the plasma and by de novo lipogenesis versus trigylceride disposal (fatty acid oxidation and the secretion of triglyceride-rich lipoproteins such as VLDL). A dysbalance between lipid acquisition and triglyceride disposal leads to a triglyceride accumulation in the cytoplasm of hepatocytes, the hallmark of NAFDL, which effects about $30 \%$ of the population in industrial countries.

The close interplay between hepatic steatosis and insulin resistance can be explained by hyperinsulinemia, a first sign of insulin resistance, which promotes transcriptional upregulation of genes that modulate lipogenesis. Additionally, several studies in both humans and animal models of NAFLD have indicated that the intracellular generation of specific lipid species are able to interact with insulin signaling, that contributes to a further hepatic insulin resistance. Especially, the formation of DAG has been associated to insulin resistance [12]. Thus, abrogation of mitochondrial glycerol-3-phosphate acyltransferase 1 (mtGPAT1) leads to lower hepatic triglyceride and DAG concentrations. Most interestingly mtGPAT1-knockout mice were protected from hepatic insulin resistance possibly due to a lower DAG-mediated PKC activation. This is in congruence with the fact that DAG-mediated stimulation of PKC $\varepsilon$ has been connected to fatty liver and hepatic insulin resistance in several rodent models 


\section{Cellular Physiology and Biochemistry}

Cell Physiol Biochem 2014;34:134-147

\begin{tabular}{l|l}
\hline DOI: $10.1159 / 000362990$ & (C) 2014 S. Karger AG, Basel
\end{tabular}

Published onlıne: June 16, 2014

Fayyaz/Japtok/Kleuser: S1P and Insulin Signaling

and in humans [13]. Activation of PKCE may interrupt insulin signaling via serine/threonine phosphorylation of the IR, a negative regulator of IR stimulation [14].

Several studies point out that saturated and unsaturated fatty acids vary in their ability to inhibit the insulin signaling pathway. Especially the saturated fatty acid palmitate diminished insulin-mediated glucose utilization whereas the unsaturated fatty acid oleate does not interact with insulin signaling but rather avoids palmitate-mediated insulin resistance [30]. This can be explained by the fact that palmitate is also a core molecule for the de novo synthesis of ceramides [15]. It has also been discussed that formation of ceramides occurs via TLR4 stimulation, whereas another study demonstrates that saturated fat-induced insulin resistance in the liver is independent of TLR4 activation [18, 31]. Nevertheless, there exist fundamental studies indicating that ceramides are involved in the progression of insulin resistance. Ceramides have been shown to activate atypical PKCs such as PKC $\zeta$, that interferes with insulin signaling [16]. In accordance, inhibition of ceramide synthesis ameliorates obesity-induced hepatic insulin resistance [32]. Treating obese mice with myriocin, an inhibitor of serine-palmitoyl transferase 1 , specifically attenuates the increase of ceramide formation without any change in DAG and improves glucose tolerance. Because of the central role of ceramides in insulin resistance, it is a matter of debate whether ceramides with distinct chain lengths differ in their ability to interrupt insulin signaling. In mammals, ceramides are formed by at least six ceramide synthases (CerSs; $1-6$ ), which are encoded by longevity assurance (lass) genes 1-6. CerS 1-6 catalyze the formation of ceramides with specific chain lengths. Indeed, it has been suggested that very long acyl chain (C22-C24) ceramides, which are formed via CerS2, modulate the appearance of insulin resistance. Thus, CerS2-knockout mice exhibit glucose intolerance despite normal insulin secretion from the pancreas. In congruence insulin receptor and Akt phosphorylation are diminished in the liver, but not in adipose tissue or in skeletal muscle. The lack of insulin receptor phosphorylation in liver correlates with its incapacity to translocate into detergent-resistant membranes suggesting that the chain lengths of ceramides regulates insulin receptor translocation into membrane microdomains [33].

But it has also been shown that palmitate induces insulin resistance independent of ceramide formation. In this manner it has been indicated that fumonisin B1, an inhibitor of CerSs, decreases palmitate-induced ceramide levels in HepG2 cells, which is not connected with an improvement of insulin signaling [10]. In this context it is of interest that in the presence of fumonisin B1 S1P-levels are enhanced and it is well known that elevated plasma S1P-levels are a feature of human and rodent obesity and diabetes [28, 29]. Indeed, most recently it has been suggested that S1P contribute to hepatic insulin resistance in vitro as well as in vivo [34]. This study demonstrates that palmitate induces an impressive formation of extra- and intracellular S1P in primary rat and human hepatocytes as well as in the liver of high fat diet-fed New Zealand obese mice. In analogy to palmitate, S1P is able to counteract insulin signaling. The inhibitory effect of S1P is receptor-dependent and is abolished in the presence of the $\mathrm{S}_{1} \mathrm{P}_{2}$-receptor antagonist JTE-013 both in vitro and in vivo. In agreement, the immunomodulator FTY720-phosphate, which binds to all S1P-receptors except $\mathrm{S}_{1} \mathrm{P}_{2}$, is not able to inhibit insulin signaling. As presented in Figure 1, these data indicate that palmitate is metabolized by hepatocytes to S1P, which acts via stimulation of the $\mathrm{S}_{1} \mathrm{P}_{2}$-receptor to impair insulin signaling [34].

An apparent contrary role of S1P on hepatic insulin signaling has also been described. The insulin sensitizing molecule adiponectin reduces ceramide levels and enhances S1P formation in the liver of mice. This change of the ceramide/S1P balance is connected with an improved insulin signaling [35]. In agreement, a modulation of the ceramide/S1P level is also visible in acid sphingomyelinase-deficient mice. In these mice glucose tolerance is improved, and glycogen and lipid accumulation is increased [36].

Insulin signaling plays also an important role in liver regeneration and proliferation [37]. It has also been suggested that S1P possesses an antiproliferative property in rat hepatocytes by activating of $\mathrm{S} \mathrm{P}_{2}$ suggesting that $\mathrm{S} 1 \mathrm{P}$ is a negative regulator in liver regeneration 


\section{Cellular Physiology and Biochemistry}

Cell Physiol Biochem 2014;34:134-147

Fig. 1. Role of S1P on hepatic insulin resistance. Stimulation of hepatocytes with palmitate induces the formation of ceramides and S1P, which can be secreted to the extracellular environment. S1P binds to the $\mathrm{S}_{1} \mathrm{P}_{2}$-receptor subtype resulting in an inactivation of insulin-mediated Akt-phosphorylation leading to an attenuation of glucokinase expression and GSK-3 $\beta$ activation. This results in an diminished glycogen synthesis.

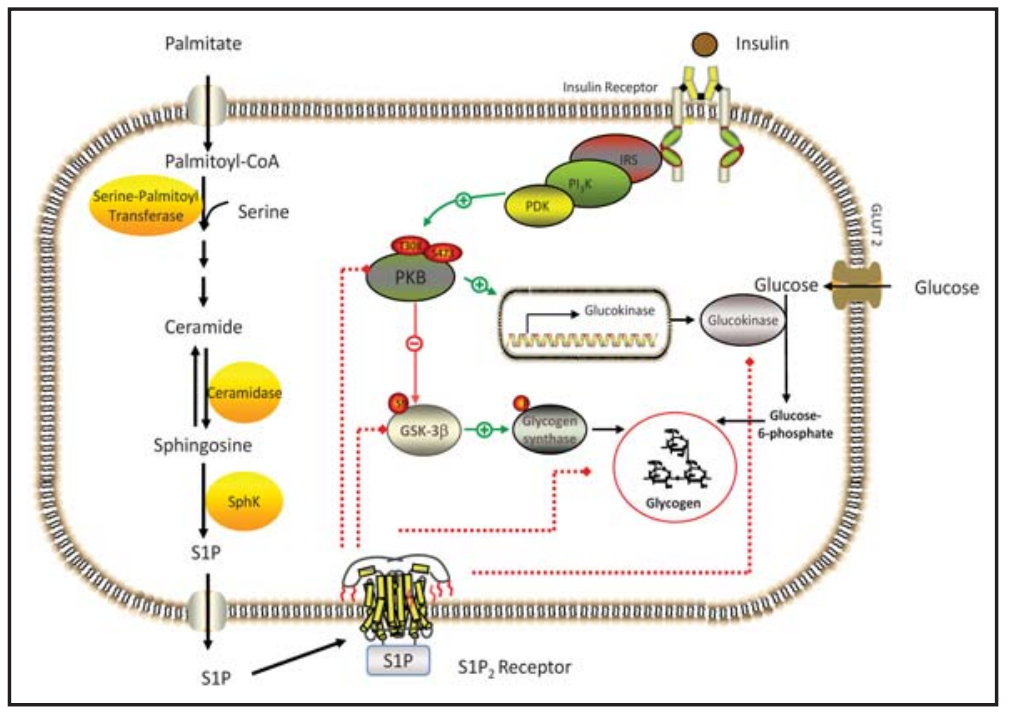

$[38,39]$. This is consistent with studies indicating that S1P diminished regeneration of liver injury caused by ischemia-reperfusion. In this model mouse survival increases from $28 \%$ to $100 \%$, when S1P formation is inhibited [40]. However it should be noted that another study indicates that repeated injection of S1P decreases hepatic and renal injury after hepatic ischemia-reperfusion, possibly through activation of $\mathrm{S}_{1} \mathrm{P}_{1}$ receptors [41]. Moreover, a variety of studies show a protective effect of S1P on survival of hepatocytes probably via Akt-activation [42, 43].

Taken together, the role of S1P and S1P-receptor subtypes on insulin resistance and Akt-signaling in the liver is not fully understood. It has been indicated that S1P possesses a protective function in hepatocytes. Nevertheless, it cannot be excluded that the S1P-mediated improvement of insulin signaling is a result of changes in the rheostat of ceramides versus S1P. But more recent data indicate that the $\mathrm{S} 1 \mathrm{P} / \mathrm{S}_{1} \mathrm{P}_{2}$ axis may counteract insulin signaling leading to insulin resistance. Thus, it would be of great interest to investigate whether inhibition of the $\mathrm{S}_{1} \mathrm{P}_{2}$ receptor subtype is a novel strategy to treat insulin resistance and diabetes mellitus type 2 .

\section{Role of S1P on insulin signaling in skeletal muscle cells}

Skeletal muscle cells are essential for the insulin-stimulated glucose disposal in the postprandial period as these cells account for up to $80 \%$ of glucose uptake and the formation of glycogen. Therefore, impaired insulin signaling in skeletal muscle cells is a crucial factor for the development of type 2 diabetes. Elevated levels of NEFA in the plasma contribute to an ectopically deposition in muscle cells as triglycerides and bioactive molecules such as DAG and sphingolipids. The formation of ceramides in skeletal muscle cells after palmitate exposure may occur either through the de novo synthesis or the stimulation of TLR4 receptors [18]. DAG and ceramides have been clearly indicated as essential signaling molecules to inhibit insulin signaling in muscle cells while the role of S1P seems to be divergent [44-46].

$\mathrm{S} 1 \mathrm{P}$ has recently been recognized in the modulation of glucose metabolism in C2C12 cells. This cell line, a subclone of the parental C2 cells, can differentiate into myotubes $[47,48]$. Therefore, these cells are used as model to study the physiological function of skeletal muscle cells. It should be noted that $\mathrm{C} 2 \mathrm{C} 12$ cells express all S1P-receptor subtypes except

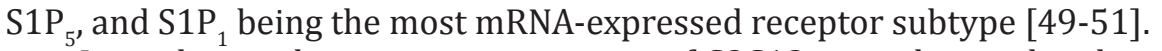

In analogy to hepatocytes, treatment of $\mathrm{C} 2 \mathrm{C} 12$ myotubes with palmitate increases the formation of intracellular S1P via an enhanced expression and activity of SphK1 [52]. This is in accordance with the fact that NEFA oversupply may activate the transcription factor 
Fig. 2. Opposing role of $\mathrm{S} 1 \mathrm{P}$ on insulin signaling in skeletal muscle cells. Stimulation of skeletal muscle cells with palmitate increases the formation of intracellular S1P via an enhanced expression and activity of SphK1 due to PPAR $\alpha$ activation. S1P can be secreted to the extracellular environment acting with the $\mathrm{S}_{1} \mathrm{P}_{3}$ receptor subtype. This induces the formation of IL-6, which mediates insulin resistance (A). Activation of the $\mathrm{S}_{2} \mathrm{P}_{2}$ receptor subtype has been indicated involved in a positive modulation of insulin signaling. In skeletal muscle cells $\mathrm{S} 1 \mathrm{P} / \mathrm{S}_{1} \mathrm{P}_{2}$ signaling induces a $\mathrm{Ca}^{2+}$-dependent generation of ROS, which can enhance the glucose uptake via GLUT4 translocation due to a phosphorylation of the insulin receptor via PTP1B (B).

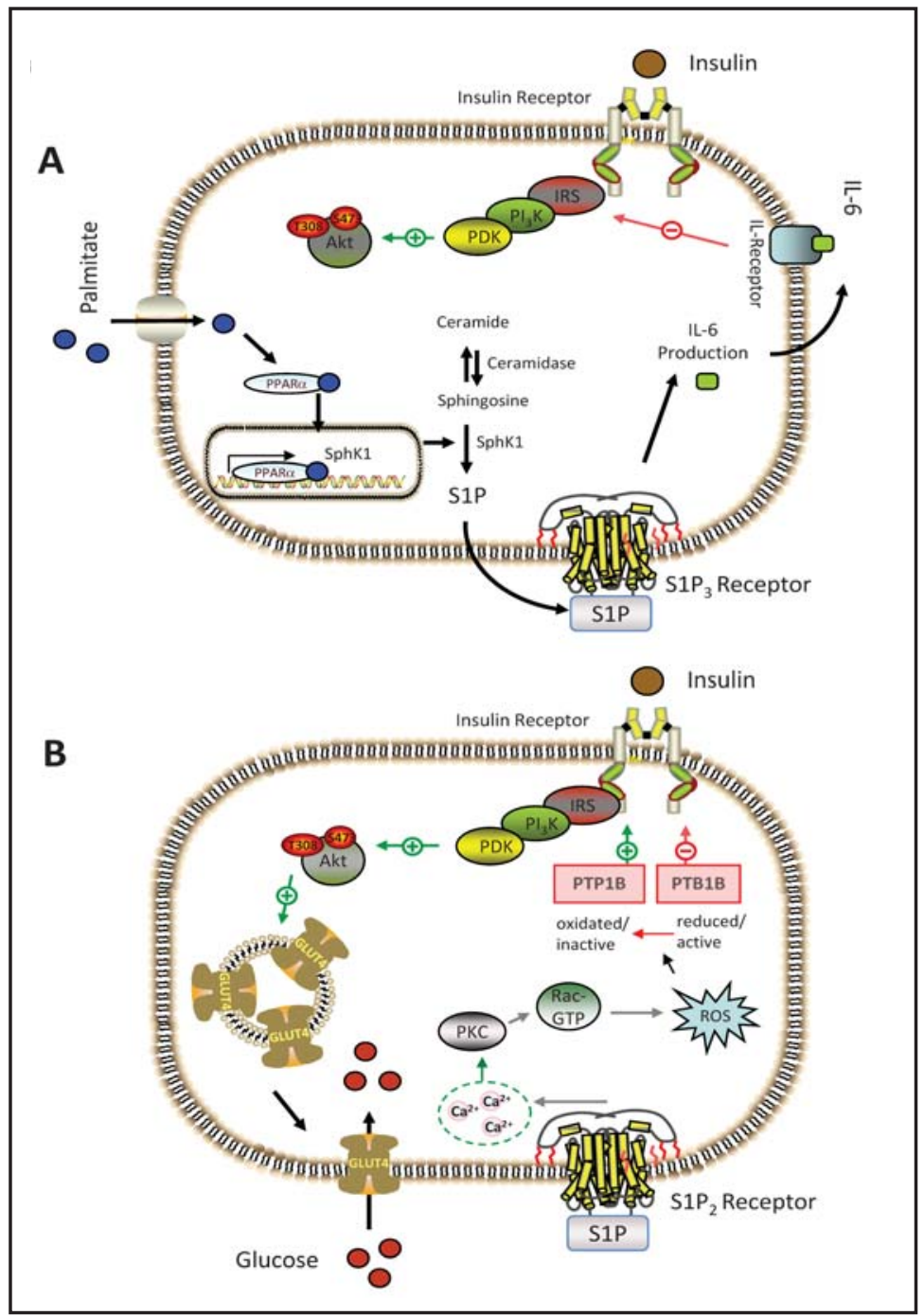

PPAR $\alpha$ in C2C12 cells and as a consequence SphK1 is upregulated on the transcriptional level. Several studies indicate that an enhancement of SphK1 and the formation of S1P contributes to the development of insulin resistance $[53,54]$. Indeed, Ross et al. suggest an interplay between SphK1 and IL-6 formation, which is presented in Figure 2A [53]. Thus, diet-induced obesity in mice induces the formation of IL-6, which is attenuated in SphK1knockout mice or in the presence of $\mathrm{S}_{1} \mathrm{P}_{3}$ receptor antagonists. IL-6, produced by skeletal muscle, is the prototype for an emerging class of cytokines known as myokines, which may mediate cross-talk between muscle and other tissues and is a crucial pro-inflammatory cytokine involved in insulin resistance [53].

Nevertheless, there are also fundamental studies indicating a synergistic action of the S1P/SphK1 axis with insulin signaling. The basal glucose uptake and the insulin-stimulated glucose uptake in C2C12 cells is markedly enhanced when SphK1 is overexpressed by adenovirus-mediated gene transfer, whereas the glucose uptake is substantially reduced when the expression of SphK1 is inhibited or the activity of SphK1 is blocked. In accordance, diabetic mice, transfected with adenovirus harbouring the human SphK1 gene, show a reduced blood glucose level but have no effect on that of normal animals. Additionally, SphK1 overexpression attenuates elevated levels of plasma insulin, NEFA and triglycerides [55]. The insulinmimetic effect of SphK1 is also visible in transgenic mice compared to wild-type animal after a 6 week high fat diet [56]. Indeed, skeletal muscle and whole-body insulin sensitivity is improved in SphK1 transgenic mice compared with wild-type mice suggesting that SphK1 is 


\section{Cellular Physiology and Biochemistry}

Cell Physiol Biochem 2014;34:134-147

\begin{tabular}{l|l}
\hline DOI: $10.1159 / 000362990$ & (C) 2014 S. Karger AG, Basel
\end{tabular}

Published onlıne: June 16, 2014

www.karger.com/cpb

Fayyaz/Japtok/Kleuser: S1P and Insulin Signaling

a crucial modulator of lipid homeostasis and insulin function in skeletal muscle under conditions of lipid oversupply. Nevertheless, this study did not indicate that S1P is responsible for the insulin-mimetic effect as an increase in intramuscular S1P content in transgenic mice does not occur [56]. This unexpected finding is consistent with those of Takuwa et al., who figured out that tissue levels of S1P is only moderately enhanced in SphK1 transgenic mice despite a high-level overexpression [57]. These data suggest that S1P levels are not only modulated by S1P-generating enzymes but also via enzymes responsible for the S1P-breakdown [58]. Nonetheless, the studies by Bruce et al. indicated that SphK1 overexpression significantly decreases ceramide levels [56]. Thus, it seems likely that the insulin-mimetic effect on metabolic homeostasis is caused by a reduction of ceramide accumulation and not due to an increased intracellular S1P-level. This is in accordance with findings that adiponectin improves local insulin sensitivity in rat skeletal muscle [59]. Overexpression of the adiponectin receptor AdipoR1 in rat skeletal muscle reduces both the formation of ceramides and S1P, which is in contrast to the action of adiponectin in hepatocytes [35]. Most interestingly, these changes are associated with an improved insulin sensitivity confirming that the diminution of ceramide levels is essential in the modulation of insulin resistance.

It has also been shown that FTY720, a structural analog of sphingosine, is able to inhibit ceramide synthesis in vitro $[60,61]$. Because ceramide accumulation in muscle is associated with insulin resistance, it is not astonishing that FTY720 prevents muscle ceramide accumulation in high fat-fed mice and subsequently improve glucose homeostasis [62]. In this study it has been indicated that high fat diet increases muscle ceramides, which is prevented by FTY720 treatment. This action is not connected with alterations in the expression of genes involved in sphingolipid metabolism. Interestingly, the effects of FTY720 on lipid metabolism are not limited to ceramides because FTY720 also prevented the high fat diet-induced increase in DAG and triglycerides in muscle. Consequently, FTY720 improves glucose homeostasis as demonstrated by a reduction in plasma insulin, an improvement in wholebody glucose tolerance, an increase in insulin-stimulated glucose uptake, and Akt phosphorylation in muscle [62]. Thus, it cannot be excluded that part of these actions are mediated via S1P-receptor signaling as FTY720 becomes active in vivo following phosphorylation to form FTY720-phosphate, and binds to all S1P-receptors except $\mathrm{S}_{1} \mathrm{P}_{2}$

On the contrary, the involvement of the $\mathrm{S}_{1} \mathrm{P}_{2}$ receptor subtype has been indicated to modulate insulin signaling in a positive manner (Figure 2B). Thus, Rapizzi et al. have reported that in $\mathrm{C} 2 \mathrm{C} 12$ myoblasts $\mathrm{S} 1 \mathrm{P} / \mathrm{S}_{1} \mathrm{P}_{2}$ signaling induces a $\mathrm{Ca}^{2+}$-dependent generation of reactive oxygen species (ROS), which can enhance the glucose uptake due to a phosphorylation of the insulin receptor via protein tyrosine phosphatase-1B (PTP1B). The beneficial role of $\mathrm{S}_{1} \mathrm{P}_{2}$ in glucose uptake by skeletal muscle can be explained through a transactivation of the insulin receptor [63].

Since these data indicate a controversial role of SphK1 and S1P on insulin resistance in skeletal muscle, future studies are required aimed to clarify the role of S1P and specific S1Preceptor subtypes on the modulation of insulin signaling.

\section{Role of S1P on pancreatic $\beta$-cell dysfunction}

The dysfunction of pancreatic $\beta$-cells and the development of insulin resistance are multifaceted with their interdependence for triggering the pathogenesis of type 2 diabetes. The fundamental role of pancreatic $\beta$-cells is to secrete insulin in response to a glucose stimulus, which is essential for maintaining plasma glucose homeostasis. Thus, $\beta$-cells must respond appropriately. An increased metabolic demand for insulin due to insulin resistance in several tissues usually precedes the development of hyperglycemia. But in an early phase pancreatic $\beta$-cells compensate for insulin resistance by hypersecretion of insulin due to modulation of $\beta$-cell function. In this manner $\beta$-cell mass is enhanced by proliferation, neogenesis, hyperplasia and hypertrophy. However, chronic exposure to elevated plasma glucose levels results in the dysfunction of $\beta$-cells and the manifestation of hyperglycemia [64]. The $\beta$-cell failure 
Fig. 3. Role of S1P on $\beta$-cell survival. The insulin sensitizing molecule adiponectin stimulates ceramidase activity yielding to the formation of sphingosine and S1P via the Adipo R1 and Adipo R2. Enhanced S1P levels can be secreted to the extracellular environment interacting with S1P receptors leading to activation of AMPK and Akt-phosphorylation influencing $\beta$-cell survival and apoptosis.

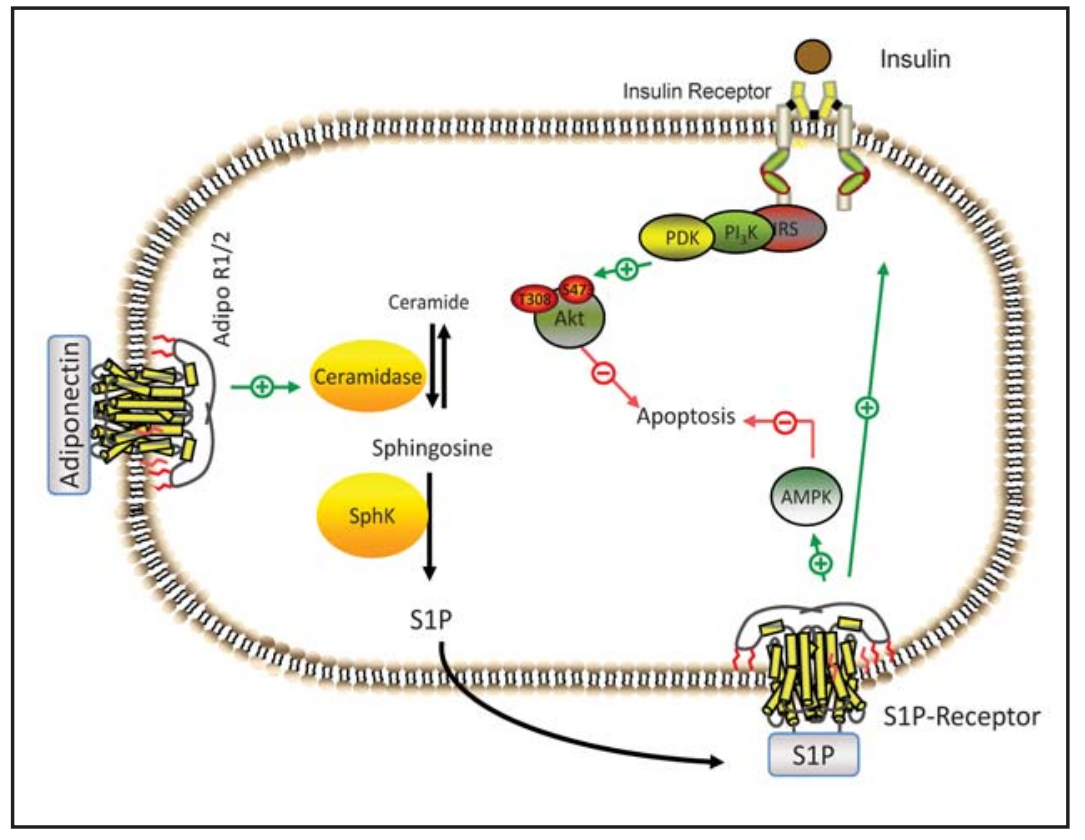

that follow the period of compensation may result from inadequate expansion of $\beta$-cell mass or failure of existing $\beta$-cells cells to respond to glucose. Thus, $\beta$-cell mass is decreased by cell death through apoptosis, necrosis and autophagy, hypoplasia and hypotrophy.

Saturated fatty acids are strongly associated with $\beta$-cell dysfunction. Most interestingly, the combination of elevated glucose and saturated fatty acid levels appears to be more disadvantageous to $\beta$-cell function than either form alone. Indeed, sphingolipid metabolites have been indicated as crucial factor in this process of glucolipotoxicity [65]. Ceramides, glycosphingolipids, S1P and gangliosides modulate many $\beta$-cell functions as apoptosis, cytokine secretion, islet autoimmunity and insulin secretion [66]. Although ceramides have long been implicated in apoptosis, their involvement in glucolipotoxicity have been indicated by the fact that saturated and not unsaturated fatty acids induce cell death via the de novo synthesis of ceramides in $\beta$-cells. Thus, in Zucker diabetic fatty rat models of type 2 diabetes the ceramide levels in islets are increased, which is accompanied by an enhancement of $\beta$-cell apoptosis. Cell death is reduced in the presence of fumonisin B1 indicating the crucial role of ceramides in $\beta$-cell dysfunction [67]. Within islets, TLR4 is expressed in $\beta$-cells and their stimulation is connected with an increased rate of apoptosis [68]. Thus it cannot be excluded that enhanced ceramide formation is due to an palmitate-mediated stimulation of TLR4 [69, 70].

Although enhanced levels of saturated fatty acids leads also to an increase of S1P, this molecule is mostly discussed as a protective sphingolipid in $\beta$-cell function. Several studies indicate that $\mathrm{S} 1 \mathrm{P}$ is able to stimulate insulin secretion in $\beta$-cells. In the clonal hamster $\beta$-cell line HIT-T15 as well as in isolated mouse islets, S1P significantly stimulates glucose-independent insulin secretion through the activation of phospholipase C (PLC) [71]. Additionally, $\mathrm{S} 1 \mathrm{P}$ has been indicated to regulate glucose-stimulated insulin secretion in $\beta$-cells. Glucose induces an intracellular rise of S1P in the mouse $\beta$-cell line MIN6 as well as in primary mouse pancreatic islets, whereas the levels of ceramide and sphingomyelin remain unchanged. The increase in S1P levels by glucose is connected with an increased glucose-stimulated insulin secretion (GSIS). It is of interest, that the glucose-mediated S1P formation is a result of an SphK2-activation. Thus, inhibition of S1P formation by the use of a SphK inhibitor and more specifically by a knockdown of SphK2 reduces GSIS, whereas a knockdown of the S1P-phosphatase, leading to increased S1P levels, rises insulin secretion [72]. Moreover, it has been suggested that glucose-dependent activation of SphK is not only responsible for insulin secretion but also for cell growth and survival of $\beta$-cells [73]. In agreement, S1P modulates also 


\section{Cellular Physiology and Biochemistry}

Cell Physiol Biochem 2014;34:134-147

\begin{tabular}{l|l}
\hline DOI: $10.1159 / 000362990$ & (C) 2014 S. Karger AG, Basel
\end{tabular}

Published online: June 16, 2014

www.karger.com/cpb

Fayyaz/Japtok/Kleuser: S1P and Insulin Signaling

cytokine-mediated $\beta$-cell apoptosis and necrosis. It has been shown that IL-1 $\beta$ and TNF- $\alpha$ induce an early and sustained increase in SphK-activity [74]. It seems likely that the formed S1P in response to IL-1 $\beta$ and TNF- $\alpha$ possesses a protective effect against cytokine-induced apoptosis in $\beta$-cells [75]. A protective role of S1P and SphK1 in $\beta$-cell survival has also been recognized under lipotoxic conditions. Lipidomic analysis revealed that palmitate at low and high glucose supplementation increases SphK1 mRNA and protein levels followed by the formation of S1P in INS-1 $\beta$-cells. Inhibition of SphK1 potentiates $\beta$-cell apoptosis induced by palmitate whereas overexpression of SphK1 significantly reduces apoptosis induced by palmitate [76]. These results are in congruence with studies performed in vivo, in which SphK1-knockout and wild-type mice were fed a high fat diet or normal chow diet. While high fat diet-fed wild-type mice develop glucose intolerance and compensatory hyperinsulinemia, all high fat diet-fed SphK1-knockout mice manifest evident diabetes and a reduction of insulin levels. The cell mass of SphK1 knockout mice is drastically reduced indicating that S1P possesses a pivotal role in $\beta$-cell survival under lipotoxic conditions [77]. In this context it should be noted that oral administration of FTY720 to diabetic $(\mathrm{db} / \mathrm{db})$ mice normalizes fasting blood glucose and prevents development of diabetes. Moreover, the islet area in the pancreases of these mice is more than 2 fold larger in response to FTY720 suggesting that the immunomodulator avoids islet damage and preserves $\beta$-cell mass by inhibiting apoptosis and increasing $\beta$-cell survival $[78,79]$.

Function of $\beta$-cells is also modulated by endogenic molecules such as lipoproteins. In murine and human $\beta$-cells, LDL decreases both proliferation and maximal glucose insulin secretion. In contrast HDL is able to enhance survival and to decrease IL-1 $\beta$ and glucoseinduced apoptosis. This effect is also observed in the absence of the HDL receptor scavenger receptor class $B$ type 1 suggesting that the protective effect is mediated via specific HDL components independent of HDL receptor binding. As S1P is able to inhibit apoptosis in $\beta$-cells and moreover the bioactive lipid is mostly carried via HDL, it can be speculated that $\mathrm{S} 1 \mathrm{P}$ is involved in HDL-mediated survival of $\beta$-cells [80].

A further endogenic molecule, adiponectin, has also been linked to modulate its function on $\beta$-cells by the formation of S1P. Several lines of evidence suggest that adiponectin promotes $\beta$-cell survival and inhibits $\beta$-cell apoptosis. Overexpression of adiponectin maintains $\beta$-cell mass and glucose homeostasis in obese (ob/ob) mice [81, 82]. Adiponectin stimulates the deacylation of ceramides yielding to the formation of sphingosine and S1P via the Adipo R1 and Adipo R2. Ceramidase activity is impaired in cells lacking both adiponectin receptor isoforms leading not only to elevated ceramide and reduced S1P levels but also to an increased susceptibility to palmitate-induced cell death. As shown in Figure 3, these observations suggest that at least part of the antidiabetic actions of adiponectin are mediated via the formation of S1P, which binds to its receptors leading to activation of AMP-activated protein kinase (AMPK). These actions of adiponectin via S1P might promote survival of $\beta$-cells, nutrient uptake and proliferation $[35,81]$.

As these studies indicate a protective effect of S1P in the development of type 2 diabetes a controversial role has been recognized in type 1 diabetes [83]. The application of a single high dose of streptozotocin (STZ) is a widely used and well-established murine model for diabetes mellitus type 1. Its diabetes inducing effect is based on the toxicity of STZ on pancreatic $\beta$-cells. Using this STZ model in rats, it has been indicated that blockade of the $\mathrm{S}_{1} \mathrm{P}_{2}$ receptor subtype attenuates STZ-induced apoptosis of $\beta$-cells. S1 $\mathrm{P}_{2}$-deficient mice display a greater survive ability lower blood glucose levels and smaller numbers of apoptotic $\beta$-cells in response to an STZ administration. Moreover, treatment with JTE-013, a specific $\mathrm{S}_{1} \mathrm{P}_{2}$ antagonist, to wild-type mice ameliorates STZ-induced blood glucose elevation and reduced the incidence of diabetes [83].

Taken together, these studies suggest that S1P modulates $\beta$-cell function in a divergent manner indicating to further study the role of S1P and its receptor subtypes in pancreatic $\beta$-cells. 


\section{Cellular Physiology and Biochemistry}

Cell Physiol Biochem 2014;34:134-147

\begin{tabular}{l|l}
\hline DOI: $10.1159 / 000362990$ & (C) 2014 S. Karger AG, Basel
\end{tabular}

www.karger.com/cpb

Fayyaz/Japtok/Kleuser: S1P and Insulin Signaling

\section{Conclusion}

Striking progress has been made in the last few years in elucidation the complex relationships between lipid metabolism and the development of insulin resistance. It is well known that NEFA contributes to the progression of insulin resistance and type 2 diabetes mellitus. At the level of the impact of NEFA on insulin resistance several lipid species such as DAG have been identified to counteract with insulin signaling. But especially saturated fatty acids and not unsaturated fatty acids seems to play a fundamental role for the development of insulin resistance. The main saturated fatty acid palmitate is required for the de novo synthesis of sphingolipids. Indeed, several studies indicate that ceramides and glucosylceramides are important molecules involved in the impairment of insulin signaling. Most recently, it has also been shown that palmitate enhances the formation of the bioactive sphingolipid S1P in several tissues such as liver, skeletal muscle and pancreatic islets. However, the role of S1P on insulin resistance is not well defined as both protective and promoting functions of the sphingolipid have been reported. In particular, the function of S1P seems to be controversial depending on the cell type and the expression of the S1P receptor profile. In hepatocytes it has been indicated that palmitate enhances $\mathrm{S} 1 \mathrm{P}$ levels, which interact via the $\mathrm{S}_{1} \mathrm{P}_{2}$ receptor subtype with the insulin-mediated Akt pathway. Existing studies on liver injury show a controversial role of S1P on liver regeneration. Divergent functions of S1P and insulin resistance have been postulated in skeletal muscle cells. On the one hand an insulin-mimetic effect of S1P has been described as S1P intensifies the action of insulin. On the other hand fatty acid oversupply is connected with an increase of S1P levels which contribute to insulin resistance probably via the formation of pro-inflammatory cytokines. Finally, $\beta$-cells are sensitive to S1P signaling. Most of the studies indicate a protective role of the sphingolipid on $\beta$-cell mass and insulin secretion. But inhibition of the $\mathrm{S}_{1} \mathrm{P}_{2}$ receptor subtype prevents the onset of type 1 diabetes suggesting that the sphingolipid contributes to an impairment of the disease.

To date the role of S1P on insulin resistance and diabetes mellitus is still not clear and further studies are needed to address the function of S1P.

\section{Acknowledgements}

This work was supported by the Deutsche Forschungsgemeinschaft (DFG) to BK (KL988/4-4).

\section{Disclosure Statement}

All authors are in agreement with the content of the manuscript. The authors declare no conflict of interest.

\section{References}

1 Reaven G: The metabolic syndrome or the insulin resistance syndrome? Different names, different concepts, and different goals. Endocrinol Metab Clin North Am 2004;33:283-303.

2 Haas JT, Biddinger SB: Dissecting the role of insulin resistance in the metabolic syndrome. Curr Opin Lipidol 2009;20:206-210.

-3 Leclercq IA, Da Silva Morais A, Schroyen B, Van Hul N, Geerts A: Insulin resistance in hepatocytes and sinusoidal liver cells: mechanisms and consequences. J Hepatol 2007;47:142-156.

4 Chiu TT, Jensen TE, Sylow L, Richter EA, Klip A: Rac1 signalling towards GLUT4/glucose uptake in skeletal muscle. Cell Signal 2011;23:1546-1554.

5 Cross DA, Alessi DR, Cohen P, Andjelkovich M, Hemmings BA: Inhibition of glycogen synthase kinase-3 by insulin mediated by protein kinase B. Nature 1995;378:785-789. 


\section{Cellular Physiology and Biochemistry}

Cell Physiol Biochem 2014;34:134-147

\begin{tabular}{l|l}
\hline DOI: $10.1159 / 000362990$ & (c) 2014 S. Karger AG, Basel
\end{tabular}

Fayyaz/Japtok/Kleuser: S1P and Insulin Signaling

6 Wang Y, Vera L, Fischer WH, Montminy M: The CREB coactivator CRTC2 links hepatic ER stress and fasting gluconeogenesis. Nature 2009;460:534-537.

-7 Wang X, Proud CG: The mTOR pathway in the control of protein synthesis. Physiology (Bethesda) 2006;21:362-369.

8 Guo S: Insulin signaling, resistance, and the metabolic syndrome: insights from mouse models into disease mechanisms. J Endocrinol 2014;220:T1-T23.

-9 Roach WG, Chavez JA, Miinea CP, Lienhard GE: Substrate specificity and effect on GLUT4 translocation of the Rab GTPase-activating protein Tbc1d1. Biochem J 2007;403:353-358.

$\checkmark 10$ Lee JY, Cho HK, Kwon YH: Palmitate induces insulin resistance without significant intracellular triglyceride accumulation in HepG2 cells. Metabolism 2010;59:927-934.

11 Samuel VT, Shulman GI: Mechanisms for insulin resistance: common threads and missing links. Cell 2012;148:852-871.

12 Neschen S, Morino K, Hammond LE, Zhang D, Liu ZX, Romanelli AJ, Cline GW, Pongratz RL, Zhang XM, Choi CS, Coleman RA, Shulman GI: Prevention of hepatic steatosis and hepatic insulin resistance in mitochondrial acyl-CoA:glycerol-sn-3-phosphate acyltransferase 1 knockout mice. Cell Metab 2005;2:55-65.

13 Samuel VT, Liu ZX, Qu X, Elder BD, Bilz S, Befroy D, Romanelli AJ, Shulman GI: Mechanism of hepatic insulin resistance in non-alcoholic fatty liver disease. J Biol Chem 2004;279:32345-32353.

-14 Samuel VT, Liu ZX, Wang A, Beddow SA, Geisler JG, Kahn M, Zhang XM, Monia BP, Bhanot S, Shulman GI: Inhibition of protein kinase Cepsilon prevents hepatic insulin resistance in nonalcoholic fatty liver disease. J Clin Invest 2007;117:739-745.

15 Ussher JR, Koves TR, Cadete VJ, Zhang L, Jaswal JS, Swyrd SJ, Lopaschuk DG, Proctor SD, Keung W, Muoio DM, Lopaschuk GD: Inhibition of de novo ceramide synthesis reverses diet-induced insulin resistance and enhances whole-body oxygen consumption. Diabetes 2010;59:2453-2464.

-16 Powell DJ, Turban S, Gray A, Hajduch E, Hundal HS: Intracellular ceramide synthesis and protein kinase Czeta activation play an essential role in palmitate-induced insulin resistance in rat L6 skeletal muscle cells. Biochem J 2004;382:619-629.

17 Lee JY, Sohn KH, Rhee SH, Hwang D: Saturated fatty acids, but not unsaturated fatty acids, induce the expression of cyclooxygenase-2 mediated through Toll-like receptor 4. J Biol Chem 2001;276:16683-16689.

18 Holland WL, Bikman BT, Wang LP, Yuguang G, Sargent KM, Bulchand S, Knotts TA, Shui G, Clegg DJ, Wenk MR, Pagliassotti MJ, Scherer PE, Summers SA: Lipid-induced insulin resistance mediated by the proinflammatory receptor TLR4 requires saturated fatty acid-induced ceramide biosynthesis in mice. J Clin Invest 2011;121:1858-1870.

19 Levade T, Jaffrezou JP: Signalling sphingomyelinases: which, where, how and why? Biochim Biophys Acta 1999;1438:1-17.

20 Chun J, Goetzl EJ, Hla T, Igarashi Y, Lynch KR, Moolenaar W, Pyne S, Tigyi G: International Union of Pharmacology. XXXIV. Lysophospholipid receptor nomenclature. Pharmacol Rev 2002;54:265-269.

21 Kohama T, Olivera A, Edsall L, Nagiec MM, Dickson R, Spiegel S: Molecular cloning and functional characterization of murine sphingosine kinase. J Biol Chem 1998;273:23722-23728.

-22 Liu H, Sugiura M, Nava VE, Edsall LC, Kono K, Poulton S, Milstien S, Kohama T, Spiegel S: Molecular cloning and functional characterization of a novel mammalian sphingosine kinase type 2 isoform. J Biol Chem 2000;275:19513-19520.

-23 Dai L, Qi Y, Chen J, Kaczorowski D, Di W, Wang W, Xia P: Sphingosine kinase (SphK) 1 and SphK2 play equivalent roles in mediating insulin's mitogenic action. Mol Endocrinol 2014;28:197-207.

-24 Spiegel S, English D, Milstien S: Sphingosine 1-phosphate signaling: providing cells with a sense of direction. Trends Cell Biol 2002;12:236-242.

25 Brindley DN, Xu J, Jasinska R, Waggoner DW: Analysis of ceramide 1-phosphate and sphingosine-1-phosphate phosphatase activities. Methods Enzymol 2000;311:233-244.

-26 Le Stunff H, Galve-Roperh I, Peterson C, Milstien S, Spiegel S: Sphingosine-1-phosphate phosphohydrolase in regulation of sphingolipid metabolism and apoptosis. J Cell Biol 2002;158:1039-1049.

27 Van Veldhoven PP: Sphingosine-1-phosphate lyase. Methods Enzymol 2000;311:244-254.

28 Kowalski GM, Carey AL, Selathurai A, Kingwell BA, Bruce CR: Plasma sphingosine-1-phosphate is elevated in obesity. PLoS One 2013;8:e72449. 


\section{Cellular Physiology and Biochemistry}

Cell Physiol Biochem 2014;34:134-147

\begin{tabular}{l|l}
\hline DOI: $10.1159 / 000362990$ & (C) 2014 S. Karger AG, Basel
\end{tabular}

Fayyaz/Japtok/Kleuser: S1P and Insulin Signaling

-29 Fox TE, Bewley MC, Unrath KA, Pedersen MM, Anderson RE, Jung DY, Jefferson LS, Kim JK, Bronson SK, Flanagan JM, Kester M: Circulating sphingolipid biomarkers in models of type 1 diabetes. J Lipid Res 2011;52:509-517.

30 Salvado L, Coll T, Gomez-Foix AM, Salmeron E, Barroso E, Palomer X, Vazquez-Carrera M: Oleate prevents saturated-fatty-acid-induced ER stress, inflammation and insulin resistance in skeletal muscle cells through an AMPK-dependent mechanism. Diabetologia 2013;56:1372-1382.

-31 Galbo T, Perry RJ, Jurczak MJ, Camporez JP, Alves TC, Kahn M, Guigni BA, Serr J, Zhang D, Bhanot S, Samuel VT, Shulman GI: Saturated and unsaturated fat induce hepatic insulin resistance independently of TLR-4 signaling and ceramide synthesis in vivo. Proc Natl Acad Sci U S A 2013;110:12780-12785.

-32 Holland WL, Brozinick JT, Wang LP, Hawkins ED, Sargent KM, Liu Y, Narra K, Hoehn KL, Knotts TA, Siesky A, Nelson DH, Karathanasis SK, Fontenot GK, Birnbaum MJ, Summers SA:: Inhibition of ceramide synthesis ameliorates glucocorticoid-, saturated-fat-, and obesity-induced insulin resistance. Cell Metab 2007;5:167179.

-33 Park JW, Park WJ, Kuperman Y, Boura-Halfon S, Pewzner-Jung Y, Futerman AH: Ablation of very long acyl chain sphingolipids causes hepatic insulin resistance in mice due to altered detergent-resistant membranes. Hepatology 2013;57:525-532.

-34 Fayyaz S, Henkel J, Japtok L, Kramer S, Damm G, Seehofer D, Puschel GP, Kleuser B: Involvement of sphingosine 1-phosphate in palmitate-induced insulin resistance of hepatocytes via the S1P2 receptor subtype. Diabetologia 2014;57:373-382.

-35 Tao C, Sifuentes A, Holland WL: Regulation of glucose and lipid homeostasis by adiponectin: effects on hepatocytes, pancreatic beta cells and adipocytes. Best Pract Res Clin Endocrinol Metab 2014;28:43-58.

- 36 Osawa Y, Seki E, Kodama Y, Suetsugu A, Miura K, Adachi M, Ito H, Shiratori Y, Banno Y, Olefsky JM, Nagaki M, Moriwaki H, Brenner DA, Seishima M: Acid sphingomyelinase regulates glucose and lipid metabolism in hepatocytes through AKT activation and AMP-activated protein kinase suppression. Faseb J 2011;25:11331144.

37 Tseng JH, Ouyang CH, Lin KJ, Yeh TS: Significance of insulin signaling in liver regeneration triggered by portal vein ligation. J Surg Res 2011;166:77-86.

- 38 Ikeda H, Satoh H, Yanase M, Inoue Y, Tomiya T, Arai M, Tejima K, Nagashima K, Maekawa H, Yahagi N, Yatomi Y, Sakurada S, Takuwa Y, Ogata I, Kimura S, Fujiwara K: Antiproliferative property of sphingosine 1-phosphate in rat hepatocytes involves activation of Rho via Edg-5. Gastroenterology 2003;124:459-469.

-39 Ikeda H, Watanabe N, Ishii I, Shimosawa T, Kume Y, Tomiya T, Inoue Y, Nishikawa T, Ohtomo N, Tanoue Y, Iitsuka S, Fujita R, Omata M, Chun J, Yatomi Y: Sphingosine 1-phosphate regulates regeneration and fibrosis after liver injury via sphingosine 1-phosphate receptor 2. J Lipid Res 2009;50:556-564.

-40 Shi Y, Rehman H, Ramshesh VK, Schwartz J, Liu Q Krishnasamy Y, Zhang X, Lemasters JJ, Smith CD, Zhong Z: Sphingosine kinase-2 inhibition improves mitochondrial function and survival after hepatic ischemiareperfusion. J Hepatol 2012;56:137-145.

-41 Park SW, Kim M, Chen SW, D'Agati VD, Lee HT: Sphinganine-1-phosphate attenuates both hepatic and renal injury induced by hepatic ischemia and reperfusion in mice. Shock 2010;33:31-42.

-42 Liu Y, Saiyan S, Men TY, Gao HY, Wen C, Zhou X, Wu CT, Wang LS, Cui CP: Hepatopoietin Cn reduces ethanol-induced hepatoxicity via sphingosine kinase 1 and sphingosine 1-phosphate receptors. J Pathol 2013;230:365-376.

-43 Osawa Y, Uchinami H, Bielawski J, Schwabe RF, Hannun YA, Brenner DA: Roles for C16-ceramide and sphingosine 1-phosphate in regulating hepatocyte apoptosis in response to tumor necrosis factor-alpha. J Biol Chem 2005;280:27879-27887.

44 Chavez JA, Summers SA: A ceramide-centric view of insulin resistance. Cell Metab 2012;15:585-94.

45 Erion DM, Shulman GI: Diacylglycerol-mediated insulin resistance. Nat Med 2010;16:400-402.

-46 Summers SA: Sphingolipids and insulin resistance: the five Ws. Curr Opin Lipidol 2010;21:128-135.

47 Blau HM, Pavlath GK, Hardeman EC, Chiu CP, Silberstein L, Webster SG, Miller SC, Webster C: Plasticity of the differentiated state. Science 1985;230:758-766.

-48 Yaffe D, Saxel 0: Serial passaging and differentiation of myogenic cells isolated from dystrophic mouse muscle. Nature 1977;270:725-727.

49 Bruni P, Donati C: Role of sphingosine 1-phosphate in skeletal muscle cell biology. Handb Exp Pharmacol 2013;216:457-467. 


\section{Cellular Physiology and Biochemistry}

Cell Physiol Biochem 2014;34:134-147

\begin{tabular}{l|l}
\hline DOI: $10.1159 / 000362990$ & (C) 2014 S. Karger AG, Basel
\end{tabular}

Fayyaz/Japtok/Kleuser: S1P and Insulin Signaling

50 Donati C, Cencetti F, Bruni P: New insights into the role of sphingosine 1-phosphate and lysophosphatidic acid in the regulation of skeletal muscle cell biology. Biochim Biophys Acta 2013;1831:176-184.

51 Meacci E, Cencetti F, Donati C, Nuti F, Farnararo M, Kohno T, Igarashi Y, Bruni P: Down-regulation of EDG5/ S1P2 during myogenic differentiation results in the specific uncoupling of sphingosine 1-phosphate signalling to phospholipase D. Biochim Biophys Acta 2003;1633:133-142.

52 Hu W, Bielawski J, Samad F, Merrill AH Jr, Cowart LA: Palmitate increases sphingosine-1-phosphate in C2C12 myotubes via upregulation of sphingosine kinase message and activity. J Lipid Res 2009;50:18521862.

-53 Ross JS, Hu W, Rosen B, Snider AJ, Obeid LM, Cowart LA: Sphingosine kinase 1 is regulated by peroxisome proliferator-activated receptor alpha in response to free fatty acids and is essential for skeletal muscle interleukin-6 production and signaling in diet-induced obesity. J Biol Chem 2013;288:22193-22206.

-54 Wang J, Badeanlou L, Bielawski JD, Ciaraldi TP, Samad F: Sphingosine Kinase 1 Regulates Adipose Proinflammatory Responses and Insulin Resistance. Am J Physiol Endocrinol Metab 2014;306:E756-768.

55 Ma MM, Chen JL, Wang GG, Wang H, Lu Y, Li JF, Yi J, Yuan YJ, Zhang QW, Mi J, Wang LSh, Duan HF, Wu CT: Sphingosine kinase 1 participates in insulin signalling and regulates glucose metabolism and homeostasis in KK/Ay diabetic mice. Diabetologia 2007;50:891-900.

-56 Bruce CR, Risis S, Babb JR, Yang C, Kowalski GM, Selathurai A, Lee-Young RS, Weir JM, Yoshioka K, Takuwa Y, Meikle PJ, Pitson SM, Febbraio MA: Overexpression of sphingosine kinase 1 prevents ceramide accumulation and ameliorates muscle insulin resistance in high-fat diet-fed mice. Diabetes 2012;61:3148-3155.

-57 Takuwa N, Ohkura S, Takashima S, Ohtani K, Okamoto Y, Tanaka T, Hirano K, Usui S, Wang F, Du W, Yoshioka K, Banno Y, Sasaki M, Ichi I, Okamura M, Sugimoto N, Mizugishi K, Nakanuma Y, Ishii I, Takamura M, Kaneko S, Kojo S, Satouchi K, Mitumori K, Chun J, Takuwa Y: S1P3-mediated cardiac fibrosis in sphingosine kinase 1 transgenic mice involves reactive oxygen species. Cardiovasc Res 2010;85:484-493.

-58 Oyama O, Sugimoto N, Qi X, Takuwa N, Mizugishi K, Koizumi J, Takuwa Y: The lysophospholipid mediator sphingosine-1-phosphate promotes angiogenesis in vivo in ischaemic hindlimbs of mice. Cardiovasc Res 2008;78:301-307.

-59 Patel SA, Hoehn KL, Lawrence RT, Sawbridge L, Talbot NA, Tomsig JL, Turner N, Cooney GJ, Whitehead JP, Kraegen EW, Cleasby ME: Overexpression of the adiponectin receptor AdipoR1 in rat skeletal muscle amplifies local insulin sensitivity. Endocrinology 2012;153:5231-5246.

-60 Berdyshev EV, Gorshkova I, Skobeleva A, Bittman R, Lu X, Dudek SM, Mirzapoiazova T, Garcia JG, Natarajan V: FTY720 inhibits ceramide synthases and up-regulates dihydrosphingosine 1-phosphate formation in human lung endothelial cells. J Biol Chem 2009;284:5467-5477.

61 Lahiri S, Park H, Laviad EL, Lu X, Bittman R, Futerman AH: Ceramide synthesis is modulated by the sphingosine analog FTY720 via a mixture of uncompetitive and noncompetitive inhibition in an Acyl-CoA chain length-dependent manner. J Biol Chem 2009;284:16090-16098.

-62 Bruce CR, Risis S, Babb JR, Yang C, Lee-Young RS, Henstridge DC, Febbraio MA: The sphingosine-1-phosphate analog FTY720 reduces muscle ceramide content and improves glucose tolerance in high fat-fed male mice. Endocrinology 2013;154:65-76.

63 Rapizzi E, Taddei ML, Fiaschi T, Donati C, Bruni P, Chiarugi P: Sphingosine 1-phosphate increases glucose uptake through trans-activation of insulin receptor. Cell Mol Life Sci 2009;66:3207-3218.

64 Virally M, Blickle JF, Girard J, Halimi S, Simon D, Guillausseau PJ: Type 2 diabetes mellitus: epidemiology, pathophysiology, unmet needs and therapeutical perspectives. Diabetes Metab 2007;33:231-244.

65 Boslem E, Meikle PJ, Biden TJ: Roles of ceramide and sphingolipids in pancreatic beta-cell function and dysfunction. Islets 2012;4:177-187.

66 Zhu Q, Shan X, Miao H, Lu Y, Xu J, You N, Liu C, Liao DF, Jin J: Acute activation of acid ceramidase affects cytokine-induced cytotoxicity in rat islet beta-cells. FEBS Lett 2009;583:2136-2141.

67 Maedler K, Spinas GA, Dyntar D, Moritz W, Kaiser N, Donath MY: Distinct effects of saturated and monounsaturated fatty acids on beta-cell turnover and function. Diabetes 2001;50:69-76.

68 Schulthess FT, Paroni F, Sauter NS, Shu L, Ribaux P, Haataja L, Strieter RM, Oberholzer J, King CC, Maedler K: CXCL10 impairs beta cell function and viability in diabetes through TLR4 signaling. Cell Metab 2009;9:125-139.

69 Eguchi K, Manabe I, Oishi-Tanaka Y, Ohsugi M, Kono N, Ogata F, Yagi N, Ohto U, Kimoto M, Miyake K, Tobe K, Arai H, Kadowaki T, Nagai R: Saturated fatty acid and TLR signaling link beta cell dysfunction and islet inflammation. Cell Metab 2012;15:518-533. 


\section{Cellular Physiology and Biochemistry}

Cell Physiol Biochem 2014;34:134-147

\begin{tabular}{l|l}
\hline DOI: $10.1159 / 000362990$ & (C) 2014 S. Karger AG, Basel
\end{tabular}

Fayyaz/Japtok/Kleuser: S1P and Insulin Signaling

7 Lee SM, Choi SE, Lee JH, Lee JJ, Jung IR, Lee SJ, Lee KW, Kang Y: Involvement of the TLR4 (Toll-like receptor4) signaling pathway in palmitate-induced INS-1 beta cell death. Mol Cell Biochem 2011;354:207-217.

-71 Shimizu H, Okajima F, Kimura T, Ohtani K, Tsuchiya T, Takahashi H, Kuwabara A, Tomura H, Sato K, Mori M: Sphingosine 1-phosphate stimulates insulin secretion in HIT-T 15 cells and mouse islets. Endocr J 2000;47:261-269.

-72 Cantrell Stanford J, Morris AJ, Sunkara M, Popa GJ, Larson KL, Ozcan S: Sphingosine 1-phosphate (S1P) regulates glucose-stimulated insulin secretion in pancreatic beta cells. J Biol Chem 2012;287:13457-13464.

73 Mastrandrea LD, Sessanna SM, Del Toro A, Laychock SG: ATP-independent glucose stimulation of sphingosine kinase in rat pancreatic islets. J Lipid Res 2010;51:2171-2180.

74 Mastrandrea LD, Sessanna SM, Laychock SG: Sphingosine kinase activity and sphingosine-1 phosphate production in rat pancreatic islets and INS-1 cells: response to cytokines. Diabetes 2005;54:1429-1436.

75 Laychock SG, Sessanna SM, Lin MH, Mastrandrea LD: Sphingosine 1-phosphate affects cytokine-induced apoptosis in rat pancreatic islet beta-cells. Endocrinology 2006;147:4705-4712.

76 Veret J, Coant N, Gorshkova IA, Giussani P, Fradet M, Riccitelli E, Skobeleva A, Goya J, Kassis N, Natarajan V, Portha B, Berdyshev EV, Le Stunff H: Role of palmitate-induced sphingoid base-1-phosphate biosynthesis in INS-1 beta-cell survival. Biochim Biophys Acta 2013;1831:251-262.

77 Qi Y, Chen J, Lay A, Don A, Vadas M, Xia P: Loss of sphingosine kinase 1 predisposes to the onset of diabetes via promoting pancreatic beta-cell death in diet-induced obese mice. Faseb J 2013;27:4294-4304.

-78 Zhao Z, Choi J, Zhao C, Ma ZA: FTY720 normalizes hyperglycemia by stimulating beta-cell in vivo regeneration in db/db mice through regulation of cyclin D3 and p57(KIP2). J Biol Chem 2012;287:5562-5573.

79 Moon H, Chon J, Joo J, Kim D, In J, Lee H, Park J, Choi J: FTY720 preserved islet beta-cell mass by inhibiting apoptosis and increasing survival of beta-cells in db/db mice. Diabetes Metab Res Rev 2013;29:19-24.

80 Rutti S, Ehses JA, Sibler RA, Prazak R, Rohrer L, Georgopoulos S, Meier DT, Niclauss N, Berney T, Donath MY, von Eckardstein A: Low- and high-density lipoproteins modulate function, apoptosis, and proliferation of primary human and murine pancreatic beta-cells. Endocrinology 2009;150:4521-4530.

-81 Holland WL, Miller RA, Wang ZV, Sun K, Barth BM, Bui HH, Davis KE, Bikman BT, Halberg N, Rutkowski JM, Wade MR, Tenorio VM, Kuo MS, Brozinick JT, Zhang BB, Birnbaum MJ, Summers SA, Scherer PE: Receptor-mediated activation of ceramidase activity initiates the pleiotropic actions of adiponectin. Nat Med 2011;17:55-63.

-82 Kim JY, van de Wall E, Laplante M, Azzara A, Trujillo ME, Hofmann SM, Schraw T, Durand JL, Li H, Li G, Jelicks LA, Mehler MF, Hui DY, Deshaies Y, Shulman GI, Schwartz GJ, Scherer PE: Obesity-associated improvements in metabolic profile through expansion of adipose tissue. J Clin Invest 2007;117:2621-2637.

83 Imasawa T, Koike K, Ishii I, Chun J, Yatomi Y: Blockade of sphingosine 1-phosphate receptor 2 signaling attenuates streptozotocin-induced apoptosis of pancreatic beta-cells. Biochem Biophys Res Commun 2010;392:207-211. 